\title{
Equal Opportunities in the Field of Sports \\ -An Investigation of History, Environmental Factors, Facility Network and Organisational Circumstances in Cross-Country Skiing and Canoeing in Finland
}

\author{
Béla József Pavelka ${ }^{1}$, Kimmo Suomi ${ }^{2}$, Hanna \\ Tietäväinen $^{3}$
}

\author{
${ }^{1}$ University of Jyväskylä, Department of Sport Sciences, researcher of Sports \\ Planning and Administration \\ ${ }^{2}$ University of Jyväskylä, Department of Sport Sciences, Professor of Sports \\ Planning \\ ${ }^{3}$ Finnish Meteorological Institute, Climate Service, Researcher
}

KEYWORDS

Services in the field of sports as a public service and as a voluntary-based civil initiative are developing on the grounds of national, regional history, environmental factors, and governmental policy, which then educate expert personnel, provide directly or induce indirectly finance for operation and facility construction. In this article the authors analyse whether equal opportunity exists in practising cross-country skiing or canoeing in Finland. Finland is one of the richest countries in Europe when it comes to natural space. The legislative basis to practice nature-based, outdoor recreational and competitive sports is laid down in the "Everyman's Right". Both of the examined sports have a long history in Finland. The weather and environment are more than suitable for practising either of these sports. The facility network is well developed for cross-country skiing but insufficient for canoeing. A magnitude difference to be found in the popularity of the two sports. By utilising the historical and natural resources and bettering organisational effectiveness, development has broad perspectives in canoeing.

equal opportunities, weather, facility, sport services, cross-country skiing, canoeing

\section{Introduction}

In contemporary society equal opportunities, social inclusion and anti-discrimination are emphasized policies (European Commission 2000). Accordance to the so-called "Peking Agreement", state-level public sport administration should provide equal opportunities for access to different sports (Suomi 2004). In this article the authors make this twist in the conventional understanding of equal 
opportunity phenomenon and analyse whether equal opportunities exist to practise two different sporting arts, if someone were to make the choice. The two sports disciplines which are going to be examined are cross-country skiing as a winter sport, and canoeing as a summer sport.

Services in the field of sport as a public service and as a voluntary based civil initiative are developing on the grounds of national, regional history, environmental factors, and governmental policy, which then educate expert personnel, provide directly or induce indirectly finance for operation and facility construction. In Finland welfare society possesses resources for investment and development. In policy recreational activities are promoted for the prevention of illnesses related to modern society, such as diabetes or cardiovascular diseases. With urbanisation an unprecedented need emerged to have nature-like space within the built-up environment for sport activities.

Finland possesses the most natural space per capita in the European Union. This applies both for forest area and for inland and coastal water surface. The legislative basis to practice nature-based, outdoor recreational and competitive sports is laid down in the "Everyman's Right", which grants free access to nature for everybody under certain conditions. Regardless of this, recreational and competitive sport alike require a variety of supporting facilities, services to induce large mass participation in outdoor activities. Both of the examined sports have a long history in Finland, yet their popularity and image are very different among everyday people concerning both recreational and competitive level. In Finland the four seasons create a highly variable environment for exercising outdoor sports. Clear seasonal differences offer ideal circumstances for both canoeing and crosscountry skiing.

Investigating canoeing in Finland for 4 years by now, the authors have been rewarded with a common regretful smile, when outsiders learn of the research topic. Cold weather, missing history, and the dangerous sort are obvious limitations for Finns wanting to be engaged in canoeing. In Finland canoeing also has an image, which can best be described as originating in J.F Cooper's The Last of the Mohicans: People who travel with a canoe, sleep in a tent, eat what is found in nature, and are left to the mercy of nature. At the same time Cross-Country Skiing is a national sport, which has a long history, is a high-level competitive branch, has a well-developed educational scheme for the young and vivid recreational movement. It is normal that Finns know how to ski, have equipment and use it too. The purpose of this paper is to examine whether the above beliefs are accurate. The authors chose four factors, which influence the opportunity of development and the possibility of involvement in sport participation.

\section{Theoretical Framework}

The pillars of this paper are different in nature. Thus methods of the investigation are tailored within the frame of the Multiple Constituency Evaluation. Taking the two sports disciplines separately as the core, stakeholders are examined respectively. The stakeholders, which have been investigated in this analysis, are not compared, however, in a competitive manner. The paper is constructed on the inductive paradigm.

\section{Research Methods and Procedures}

Qualitative and quantitative data have been collected in various ways for this analysis. Each section of the work needed a different approach, thus methods were adapted to the requirements of each chapter. The history section of this article is based on the broad literature available, and a semistructured, in-depth interview with Janne Vilkuna, professor of Museology at the University of 
Jyväskylä. Vikuna has researched remaining watercrafts and other sport/transport devices for decades. $\mathrm{He}$ is one of the most acknowledged people in the field in Finland. The interview took place on $5^{\text {th }}$ January 2007.

For the environment and weather study observation data from the Finnish Meteorological Institute (FMI) were used. The three weather stations representing southern, middle and northern Finland, were Vantaa (lat: $60^{\circ} 19^{`}$ lon: $24^{\circ} 57^{`}$ ), Jyväskylä (lat: $62^{\circ} 24^{`}$ lon: $25^{\circ} 40^{\circ}$ ), and Sodankylä (lat: $67^{\circ} 22^{\prime}$ lon: $26^{\circ} 37^{`}$ ). The study period ranges from 1996 to 2005 . The temperature data of surface water was obtained from the Finnish Environment Institute (SYKE) and is collected from the nearest possible locations to the selected weather stations. Each day during the 10-year period was classified based on different weather variables into one of six categories ranging from "ideal" to "impossible" (Tables 1 and 2). The variables were studied only during an "active time of a day".

Facility related data is based on the Finnish Sports Facility Data Bank (LIPAS)

The data used in the organisational structure and operation part of the article originate from interviews with representatives of the concerned NSFs, Sport Departments of the three municipalities (Vantaa, Jyväskylä, Sodankylä) and clubs from the two concerned sports disciplines. Information published on their official internet home pages also was obtained. Data from the National Sport Survey 2001-02 and 2005-06. Telephone and e-mail interviews were performed in January-March 2007.

\section{History}

Finland always has had a low density of population. In wintertime for personal traffic, hunting and transportation of small goods cross-country skis and the sledge were the most suitable and fastest equipment. Since roads did not exist, in summertime waterways provided access to the deep wilderness. The first persistent inhabitants of inland Finland intruded across the land via waterways on rowing boats and canoes, which allowed the transportation of larger amount of goods (Suomela 1944).

In Finland and the Karelian region of Russia various cliff paintings from the Stone Age show both skiers' and paddlers' figures (Autio 1981). A number of related archaeological findings including both skis and paddles also exist, dated to 3000-4500 BC (Vilkuna 1995 and 1998). Whereas the use of skis is not questioned, there is a debate over the paddle-findings. Some claim that the rowing-like movement (i.e.: sitting with one's back to the direction of movement, having fixed oars on the watercraft) is as old as canoeing (i.e.: sitting face-forward, holding the paddles in hand), and do not consider the relationship of the findings to be proved for either sport. This is strongly debatable, however. Some native population in Polynesia, in the Pacific islands and in Amazonia still use punts, which were supposedly the first intentionally shaped on-water traffic device. Remains of them have been found in Finland as well. Those boats must be propelled with paddling movement, since the mechanical structure does not allow a support point for fixing oars.

Skiing skills were important in the defence of the country on numerous occasions throughout history. As early as the battle of Joutselkä in 1555 this expertise was decisive against all odds. Later on the training of skiing skills became an essential part of the PE programme in educational institutions as well. At the beginning of the $20^{\text {th }}$ century one of the main figures in Finnish Sport, Lauri "Tahko" Pihkala, coined the slogan "Finland's protection on skis" - Suksissa Suomen suoja - which set up a line in education, in civil guard movements and in military training (Paasilinna 1998). Since every Finn is taught cross-country skiing in the early school age, in adulthood every inhabitant possesses knowledge of basic skills to be able to enjoy the activity in safety without expert supervision. Being 
part of the obligatory curriculum, talent selection is done simultaneously. Successes of Finnish elite skiers at international level have had been in continuous supply during the modern sporting era. Speaking about the competitive cross-country skiing we have to mention the sporting diplomatic struggle between the Nordic countries, about the direction in which the sport develops. In Finland the sport was pursued more on splendid slopes and flatland, whereas in Norway and Sweden telemark-like skiing in a mountainous environment was rather more typical (Jussila 1998).

Seeing the master carvings of archaeological paddles, it is highly probable that ancient canoeing had a flourishing culture. It is not clear why this culture declined, but with the development of craftsmanship and trade the size of the boats increased. The growing tar transportation (Vilkuna 1998) and fishing industry raised the need for that. Additionally, so-called church boats were used to get to church from the rural areas (Suomela 1944) for hundreds of years. With the increase in population the boats also grew in size, so that by the 1800s one could accommodate up to 40 people. Recreational boating and canoeing started in Finland around the end of the $19^{\text {th }}$ century. The first commercial river rapid rides started as early as 1908 in Southern Finland, and in 1920 the first tourist rafting company was found in Kuusamo. In these activities, customers were only passengers on boats, which were driven by expert skippers (Paakkinen 2002). Recreational canoeing has been a guided discipline in Finland ever since.

\section{Environment and weather}

This weather study was made using the Finnish Meteorological Institute's (FMI) weather observation data from three weather stations representing southern, middle and northern Finland. The weather stations are situated in Vantaa (lat: $60^{\circ} 19^{`}$ lon: $24^{\circ} 57^{`}$ ), Jyväskylä (lat: $62^{\circ} 24^{`}$ lon: $25^{\circ} 40^{\circ}$ ), and Sodankylä (lat: $67^{\circ} 22^{`}$ lon: $26^{\circ} 37^{\circ}$ ). The study period ranges from 1996 to 2005 . Each day during the 10-year period was classified based on different weather variables into one of six categories ranging from "ideal" to "impossible" (Tables 1 and 2). The variables were studied only during an "active time of a day" that was defined to range from 06UTC to 18UTC. The empirical base of the calibration was set so that recreational sport is done mainly in ideal and in good circumstances. Occasional practisers, hobby sportsmen and competitors alike enjoy their time out. In suitable conditions active participants still go out but occasional recreation is unusual. In poor weather, mostly only athletes take the chance. In extreme conditions even competitors seek alternative exercise and rarely is anyone seen on the tracks or on water.

Table 1. Weather classifications for cross-country skiing.

\begin{tabular}{lllllll}
\hline & Ideal & Good & Suitable & Poor & Extreme & Impossible \\
Air temperature $\left({ }^{\circ} \mathrm{C}\right)$ & over -5 & -5 to -7 & -8 to -12 & -13 to -17 & under -17 & \\
Wind speed $(\mathrm{m} / \mathrm{s})$ & 0 to 2 & 3 to 4 & 5 to 7 & 8 to 10 & over 10 & \\
Precipitation $(\mathrm{mm})$ & under 0.3 & 0.3 to 0.9 & 1.0 to 4.0 & 4.1 to 8.0 & over 8.0 & \\
Snow depth $(\mathrm{cm})$ & over 30 & 21 to 30 & 16 to 20 & 11 to 15 & 1 to 10 & under 1 \\
\hline
\end{tabular}

Air temperature is defined as the average temperature during the active time. Wind speed is ranked by the highest mean wind speed (10 minutes average) measured during the active time. Precipitation is the 12-hour rainfall measured at 18UTC. Critical variables that set the limit between possible and impossible exercising days for the sports are snow depth for cross-country skiing and surface water temperature for canoeing. Snow depth is measured each day at 06UTC. The surface water data was obtained from the Finnish Environment Institute (SYKE) and is collected from the nearest possible locations to the selected weather stations. The temperature of the surface water is 
measured once per day when waters are open. The time between freezing and melting sets the limit for impossible canoeing conditions.

Table 2. Weather classifications for canoeing.

\begin{tabular}{lllllll}
\hline & Ideal & Good & Suitable & Poor & Extreme & Impossible \\
Air temperature $\left({ }^{\circ} \mathrm{C}\right)$ & over 20 & 15 to 20 & 10 to 15 & 5 to 10 & under 5 & \\
Wind speed $(\mathrm{m} / \mathrm{s})$ & 0 to 2 & 3 & 4 to 6 & 7 to 9 & over 9 & \\
Precipitation $(\mathrm{mm})$ & under 0.3 & 0.3 to 0.9 & 1.0 to 4.0 & 4.1 to 8.0 & over 8.0 & \\
Surface water $\left({ }^{\circ} \mathrm{C}\right)$ & over 21 & 16 to 21 & 10 to 15 & 4 to 9 & 0 to 3 & under 0 \\
\hline
\end{tabular}

The study was made by first dividing each day between 1.1.1996 and 31.12.2005 into one of the six categories according to the classifications listed in Tables 1 and 2. This was done for both of the sports separately. The weakest variable set the daily level. A one-year average for the number of ideal, good, suitable, poor, extreme, and impossible exercising days was then calculated by dividing the number of days in each category by the number of years, i.e. by ten.

The average temperature of the air is respectively higher in the spring season compared to water temperature. From the middle of the summer onward the opposite is true. Average temperature of surface waters in the past century statistically did not change, however in certain lakes a large deviation is observed in maximum temperatures. Lakes with still water react more sensitively to air temperature changes, but even a minimal flow mixes water layers effectively, thus surface water temperatures have an even distribution (Korhonen 2002). There has been no significant warming trend in air temperature in northern Finland during the modern sporting era, even though shorter warming and cooling periods are observable. It is noticeable that the past two decades represent a warming period (Lee 2000). This is interpreted as global warming caused by human activity, however, and it is in the focus of policymakers too (Alley 2007).

The number of ideal to impossible days for practising cross-country skiing and canoeing per year in the three different locations is given in Table 3. The distribution of ideal, good, and suitable days is as expected: the number of at least suitable days for practising cross-country skiing increases substantially towards the north, and it decreases for canoeing. Ideal and good days occur more often for cross-country skiing than for canoeing, for all locations. However, the number of at least suitable canoeing days in the southern and middle part of the country is clearly larger than for cross-country skiing.

In northern Finland the number of possible skiing days per year is greater than the number of impossible ones. There was only one day per year with ideal surface water conditions, while in southern and middle Finland the number was 15 to 35 . The number of at least suitable days is smaller for canoeing than for cross-country skiing. This is mainly due to the temperature of the surface water. Passionate practisers have the chance to go out to engage in either sport for a number of days in the northern part of the country.

According to the statistics the weather is rarely ideal for either sport. However, it should be noted that the stipulated wind speed limit was rather low for all categories. In many cases it was just the wind speed that dropped on some particular day from the ideal class to a lower category.

Experimental observation proves that on many days there are a number of hours which are ideal for outdoor sport, but the rest are poor or extreme. In early spring, for example, temperature variations during the day can be as large as 15 to 20 degrees Celsius, the coldest time being in the early morning. In summertime respectively morning and evening hours can be calm, whereas in daytime the wind blows considerably but the temperature does not change notably. People who can 
adapt their schedule to the random changes in weather can more often find the ideal occasion for outdoor activity.

Table 3. Number of days for practicing cross-country skiing and canoeing per year in the three location

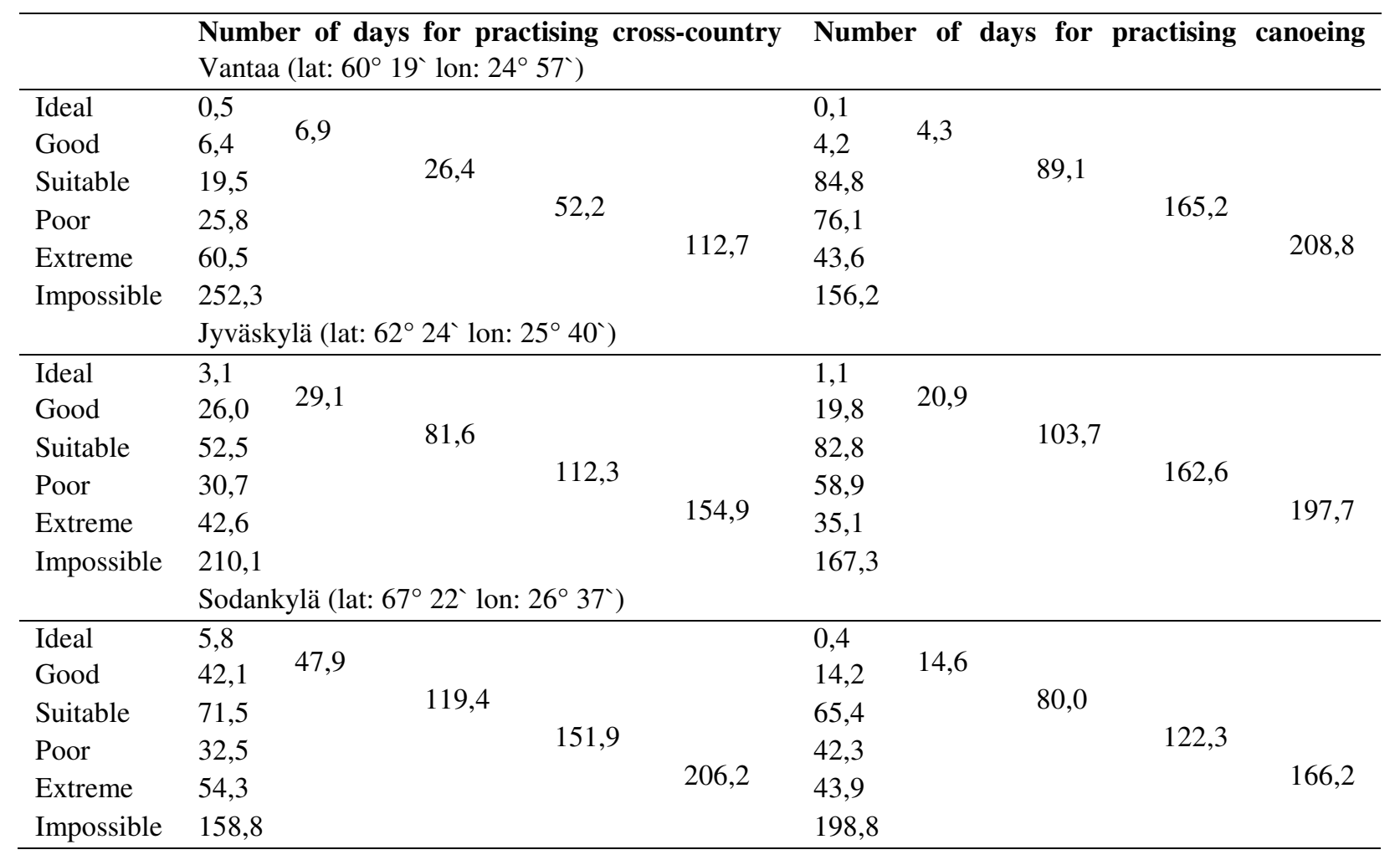

\section{Facilities and supporting constructions}

\section{Organisational Structure and Operation}

In Finland's sport culture recreational activities were always more emphasized than high-level sport participation. The country's health issues have been prioritised by national and local governmental policies. Elite sport finance is backed mainly by private sponsorships and own generated resources. Governmental and NOC support for associations and individuals contribute at most $30 \%$ of the finance for the actual sporting practice. Governmental subsidy is targeted for organisations with an active and versatile youth sport program and for groups with special needs. NOC supports both junior and senior elite sport.

Suomen Latu, the Finnish outdoor recreational sports association, has 219 local associations or clubs with 73,000 members nationwide. In the Latu-clubs various outdoor recreation pursuits such as cross-country skiing and canoeing are practised, according to the season. The association and its local sections are co-organisers of hundreds of local and national recreational sports events throughout the year. The yearly program of the national organisation includes about 100 recreational skiing events and two (2) events for canoeing. It is remarked that local sections may have additional activities. The Jyväskylän Latu club has a shade over 2000 members.

In its registry the Finnish Ski Federation lists 609 clubs which practise cross-country skiing further clubs may practise other disciplines, like alpine or ski jumping. There are 179,000 members in the cross-country skiing clubs, and 10,256 competitive licences were issued for the 2006-2007 season 
in all the age groups and levels. The federation estimates that around 747,000 adults and 190,000 juniors (under 18 years) are engaged in cross-country skiing activity at different levels. According to the National Sports Survey 2005-2006, 19.2\% of the adult population and 2\% of young people (under 18 years) are engaged in regular recreational or competitive cross-country skiing. Compared to the 2001-2002 survey this is a slight decrease (of $0.4 \%$ ). The two independent sources confirm each other. In the event calendar of the federation over 200 competitions or recreational events are listed for different age groups. Every year 15 mass events are organised in cross-country skiing, with 500 to 7,000 participants in each event.

In Jyväskylä the Sports Department maintains over $220 \mathrm{~km}$ cross-country skiing tracks in 14 locations of the town and their connecting tracks. In the town registry 8 clubs are to be found which practise cross-country skiing at some level. In these clubs several thousands of members are registered. There are two large cross-country skiing specialised racing clubs in the town. These clubs have a vibrant youth educational scheme, including regular activities with coach supervision. The Sports Department provides maintained tracks for cross-country skiing as a public service free of charge. Citizens who are not members of a club are eager to use the tracks for winter outdoor activity. Services along trails differ from place to place. Lighting, heating and shelter, and a parking lot are standard; toilets, changing rooms, and restaurant facilities are less common. In the budget of the Sports Department about $€ 150,000$ is dedicated to cross-country skiing related services yearly.

Table 4. Participation in cross country skiing and in canoeing in Finland

\begin{tabular}{lll}
\hline & Cross-Country Skiing & Canoeing \\
Number of clubs & 609 & 68 \\
Amount of club members & 179000 & 5753 \\
Estimated active practisers & 937000 & 21000 \\
Issued licenses & 10256 & 256 \\
Official events/year (2005) & 215 & 43 \\
\hline
\end{tabular}

In the Finnish Canoe Federation (FCF) there are 68 clubs registered. The federation reported 5753 members in these clubs. For the 2006 season 256 competitive licenses were issued for all age groups and levels. The FCF estimates the number of active paddlers about 100,000. The National Sport Survey found that $0.4 \%$ of the population (young and adults together) is interested in canoeing, which is about 21,000 people. The two data sources do not reinforce each other. Compare to 20012002 a statistically non-significant increase is found in participation, whereas the media speak of a "canoe boom" in Finland. In the event calendar about 50 events are listed yearly. One mass event is organised with the participation of the FCF. There are about 1000 participants every summer.

In Jyväskylä municipality two canoe clubs are registered. There are around 300 members in these clubs. Besides the clubs, entrepreneurs provide recreational canoeing for a wider public in the form of canoe rental and tour operation. Business-operated canoe programs are more popular in the country as a whole than club-based activities. Yearly about $€ 50,000$ is allocated in the budget of the Sports Department to "swimming beaches" and "other recreational outdoor places". A fraction of this amount of money is spent on canoeing in Jyväskylä.

\section{Conclusion}

The history of the two examined sports in Finland is immemorial. Their importance and role, however, steered development in different directions. Skiing has not only been a form of personal transportation, but also a key element in the defence of the country. Due to this skiing is taught in 
obligatory education and in military service. Practically every Finn learns how to ski. On the other hand, the once flourishing canoeing culture diminished and the sport remained as a transportation tool for some fishermen and as a pastime for holiday makers. Recently recreational canoeing has become more popular, but facility and organisational backing is insufficiently developed to serving mass participation.

During the modern sporting era, environment and weather factors were always at least suitable for both of the sports. The global warming trend predicts that in the future meteorological circumstances are going to be preferable for canoeing than for cross-country skiing. The open water season is going to be longer and the snow-covered season shorter. It is however true that the snowcovered season was and is longer in Finland than in many other countries. Weather circumstances and environment are good for skiing, but not a barrier to the development of canoeing in Finland.

Facility network is well developed for skiing. Both recreational and competitive participants can find good services. Supporting facilities for canoeing rarely exist. Existing ones are mostly do not satisfy the requirements of a modern recreational sport facility, e.g. there is a lack of changing rooms, showers, toilets, space for club activities etc.

Skiing has a strong and active organisational background in this country at both a national and local level. Activities range from the highest elite sport to the "Sunday-skier" level. Non-active people often volunteer for skiing events, due to the noble values of skiing in the society. Skiing bears strong cultural, national values in Finland. Canoeing possesses weak organisational guidance. Despite the large amount of privately owned canoes and kayaks, participation in organised activities is low. By utilising the historical and natural resources and bettering organisational effectiveness, development of canoeing has a broad perspective. Local governmental support, in direct and indirect forms, is in balance with the number of participants in these sports.

\section{REFERENCES}

Alley, R. et al. (2007). Climate Change 2007: The Physical Science Basis, Summary for Policymakers, 10th Session of Working Group I of the IPCC. Paris, February 2007.

Autio, E. (1981). Karjalan kalliopiirrokset. Keuruu.

European Commission (2000). Council Decision of 27 November 2000 establishing a Community action programme to combat discrimination (2001 to 2006).

Jussila, P. (1998). Suomen hiihto. Otawa, Helsinki.

Korhonen, J. (2002). Water temperature conditions of lakes and rivers in Finland in the 20th century. Suomen Ympäristö nro 566. Helsinki: Finnish Environment Institute.

Kotivuori, H. (2006). Savukosken kivikautinen mela, RATIO Lapin Maakuntamuseon tiedotuslehti 2006, p. 3637, Rovaniemi: Lapin maakuntamuseo.

Lee, S. E., Press, E. C., Lee, A. J. (2000). Observed climate variations during the last 100 years in Lapland, northern Finland. International Journal of Climatology, Volume 20, Issue 3, p. 329-346.

Naskali, E. (2001). On Ancient Skis. 2nd FIS Ski Historical Conference, Esaprint Lahti.

Paakkinen, E. (2002). Koskenlasku \& melonta. Lahti: Exterme Addventure Finland.

Paasilinna, A. (1998). Tales of the Snowfields. Helsinki: Tietosanoma.

Suomela, U. K. L.(1944). Suomen urheilun historia. Helsinki: KIVI

Suomi, K. (2004). Multiple constituency Evaluation in sport policy. European Journal of Sport and Society, 2/2004, p.135-142. 
Suuri kansallinen liikuntatutkimus 2001 - 2002: aikuisliikunta (2002) Helsinki : Suomen Kuntourheiluliitto.(Suomen Liikunnan ja Urheilun julkaisusarja; 5).

Suuri kansallinen liikuntatutkimus 2001 - 2002: lasten ja nuorten liikunta (2002) Helsinki :Nuori Suomi (Suomen Liikunnan ja Urheilun julkaisusarja; 4).

Suuri kansallinen liikuntatutkimus 2005 - 2006: aikuisliikunta (2006) Suomen Kuntoliikuntaliitto. Helsinki (Suomen Liikunnan ja Urheilun julkaisusarja ; 5/06).

Suuri kansallinen liikuntatutkimus 2005 - 2006: lasten ja nuorten liikunta (2006). Helsinki Nuori Suomi. (Suomen Liikunnan ja Urheilun julkaisusarja ; 4/06).

Vilkuna, J. (1995). Viitasaaren muinaissuksi ja Laukaan muinaismela. Keski-Suomen Museon Tiedote 1/95, Jyväskylä.

Vilkuna, J. (1998). Finska båtan från förhistorik tid - Suomen esihistoriallisen ajan veneet. Människor och båtar i Norden. Sjöhistoriska museets årsbok, (p. 256-267), Stockholm. 